\title{
What mathematical competencies does a citizen need to interpret Mexico's official information about the COVID-19 pandemic?
}

\author{
Mario Sánchez Aguilar $^{1}$ (D) $\cdot$ Apolo Castaneda ${ }^{1}$ (iD
}

Accepted: 20 June 2021 / Published online: 23 July 2021

(C) The Author(s), under exclusive licence to Springer Nature B.V. 2021, corrected publication 2022

\begin{abstract}
We report a study on mathematical literacy with special emphasis on health literacy. In particular, we identify and characterize the mathematical competencies that a citizen needs to interpret the official information on the COVID-19 pandemic as experienced in Mexico. To achieve this, we analyze the daily reports on the pandemic issued by the Mexican Ministry of Health, using the framework of mathematical competencies as a theoretical lens. Our results show that there are five necessary competencies to interpret the official information: mathematical communication, mathematical representation, mathematical symbols and formalism, mathematical modeling, and mathematical reasoning competency. After characterizing and illustrating these competencies, we close the paper with a reflection on the importance of mathematical literacy in a pandemic world.
\end{abstract}

Keywords COVID-19 pandemic $\cdot$ Mathematical literacy $\cdot$ Health literacy $\cdot$ Mathematical competencies

\section{Introduction}

There are several theoretical perspectives in the field of mathematics education claiming that citizens of contemporary societies must possess basic mathematical literacy. The arguments that support the need for this mathematical literacy are varied: mathematical literacy is indispensable in the maintenance of democratic societies (Niss, 2003), it helps to produce

Mario Sánchez Aguilar

mosanchez@ipn.mx

Apolo Castaneda

acastane@ipn.mx

1 Instituto Politécnico Nacional, CICATA Legaria, Programa de Matemática Educativa, Calzada Legaria No. 694, Col. Irrigación, C.P., 11500 Mexico City, Alcaldía Miguel Hidalgo, Mexico 
functional and critical citizens (Skovsmose, 1998), and it promotes civic understanding and engagement in matters of crucial importance in modern societies (Engel, 2019).

The COVID-19 pandemic is a situation where this need for basic mathematical literacy among citizens becomes palpable and evident. Much of the information provided to the general public on the development of the pandemic is expressed in mathematical terms. A thorough understanding of this information requires certain mathematical equipment among citizens, but what are the characteristics of such mathematical equipment? In other words, what kind of mathematics does an ordinary citizen need to know to interpret information about the coronavirus pandemic?

In this study, we investigate the kind of mathematical competencies that a citizen needs to possess to interpret the official information about the COVID-19 pandemic. Taking as reference the daily public reports issued by the Mexican Ministry of Health about the pandemic, we conduct an analysis to identify the mathematical competencies needed to decode the official information on the development of the pandemic.

Our study represents an effort to identify mathematical notions and competencies that are basic for the communication between government agencies and citizens in a time of crisis and which nurture our ability to understand health-related information. An analysis like this could allow a critical reflection on the mathematical curriculum and how it prepares or fails to prepare citizens for a global crisis like the one we are experiencing.

To contextualize our study in the landscape of mathematics education, in the following section, we present an overview of notions related to the mathematical education of citizens. Later, we present a synthesis of the conceptual framework of mathematical competencies and its terminology (Niss \& Højgaard, 2011, 2019), which we use as tools to analyze daily public reports issued by the Mexican Ministry of Health.

\section{Placing the study in the landscape of mathematics education}

This study is related to citizens' ability to put their mathematical knowledge into practice in the context of a global health emergency. A study like this one may be related to different notions and research areas of mathematics education.

This study is connected to notions that have tried to capture people's ability to use and interpret mathematics in extra-mathematical contexts and situations that are individually and socially relevant. One of the oldest related notions is that of numeracy, which is estimated to have first appeared in The Crowther Report of 1959 (see Brown et al., 1998). The conceptualization of numeracy has been changing over time. An early conceptualization of this notion is "the ability to process, communicate, and interpret numerical information in a variety of contexts" (Askew et al., 1997, p. 336). However, there are broader conceptualizations that interpret the notion as the ability "to use mathematics effectively to meet the general demands of life at home, in paid work, and for participation in community and civic life" (Australian Association of Mathematics Teachers, 1997, p. 15).

We could also consider notions such as critical mathematical literacy (Frankenstein, 1990) and mathemacy (Skovsmose, 1994), which can be conceptualized as approaches that conceive mathematical knowledge as fundamental for the formation of critical citizens able to coexist and maintain democratic societies. These theoretical approaches focus on understanding and illustrating how mathematical knowledge can provide individuals with a critical understanding of their own social and political environment. 
The study could also be connected to notions closer to the area of statistics education like statistical literacy (Gal, 2002; Watson \& Callingham, 2003) and civic statistics (Engel, 2019). Although there are different nuances in the conceptualizations of statistical literacy and derived notions such as civic statistics, they share the idea that the ability to understand and apply statistical knowledge is fundamental to different aspects of the lives of citizens of contemporary data-driven societies (Sharma, 2017).

As noted by Niss and Jablonka (2014), although the meanings of these related notions may vary, what they have in common is that

they stress awareness of the usefulness of and the ability to use mathematics in a range of different areas as an important goal of mathematics education. [These notions] are associated with education for the general public rather than with specialized academic training. (Niss \& Jablonka, 2014, p. 392).

We share this position to encompass these notions in the overarching concept of mathematical literacy, which is defined as:

An individual's capacity to formulate, employ, and interpret mathematics in a variety of contexts. It includes reasoning mathematically and using mathematical concepts, procedures, facts, and tools to describe, explain, and predict phenomena. It assists individuals to recognise the role that mathematics plays in the world and to make well-founded judgments and decisions needed by constructive, engaged and reflective citizens. (Niss \& Jablonka, 2014, p. 392)

If we consider that the public reports about the pandemic that we use as empirical basis for this study are aimed at common citizens, then we can think of an intersection of this research with the field of study called adults learning mathematics (Coben \& O'Donoghue, 2014). This is because one of the focuses of this field of study is the use of mathematics in adult life. Of particular relevance to this research are those studies that have explored the relationship between mathematical literacy and adults' health (e.g., Gigerenzer \& Edwards, 2003; Heilmann, 2020; Zeuner et al., 2020). This type of study shows a connection between mathematical literacy and the ability to understand health-related information and make responsible decisions based on this understanding. A theoretical concept emanating from this research area, which is useful to frame our study, is that of health numeracy: "the degree to which individuals have the capacity to access, process, interpret, communicate, and act on numerical, quantitative, graphical, biostatistical, and probabilistic health information needed to make effective health decisions" (Golbeck et al., 2005, p. 375).

Thus, we conclude this section by stating that in this paper, we report on a study on mathematical literacy but particularly related to the notion of health numeracy. More precisely, we focus on identifying and characterizing the mathematical competencies necessary for a citizen to interpret official information related to a health emergency.

\section{The study context}

This paper and the study that it reports on were developed under lockdown during the COVID19 global pandemic. The first COVID-19 outbreak was identified in Wuhan, China, in 
December 2019. Since then, the virus has gradually spread around the world. The Government of Mexico - the country where this study was conducted - had the opportunity to observe the management of the pandemic by other nations, before implementing measures to mitigate it locally. Among the measures implemented by the Mexican government are the daily reportsa kind of press conference - on the evolution of the pandemic issued by the Mexican Ministry of Health.

From February 29, 2020, until the day we submitted the first version of this paper (May 31, 2020), the Mexican government issued a daily report for the population. This report is broadcast every afternoon from 7:00 p.m. to 8:00 p.m. through different mass media such as television, radio, and the Internet. In addition to reporting on the evolution of the pandemic locally and globally, these reports serve as a communication platform between government officials and society. Through these reports, the Mexican population is informed about the measures and precautions to be taken during each phase of the pandemic. The questions and doubts expressed by the journalists covering the transmission of the reports are answered by health officials and medical specialists. Video recordings of the daily reports are stored on the YouTube channel of the Mexican Ministry of Health, whence we accessed them for inclusion in this study.

All daily reports began with a section called "technical report" that lasts approximately $20 \mathrm{~min}$ and which presents figures, graphs, estimates, tables, and other data focused on illustrating the development of the pandemic in Mexico and the world. It is precisely on these technical reports that we focused the analysis presented in this article. To conduct this analysis, we rely on a framework of mathematical competencies, which we briefly introduce next.

\section{Mathematical competencies: a framework for the analysis}

To identify and characterize the mathematical knowledge and skills needed to have a robust understanding of the official information about the COVID-19 pandemic as experienced in Mexico, we adopted the framework of mathematical competencies developed by Niss and Højgaard (2011, 2019).

One of the reasons for adopting this framework is the influence and tradition that it has had for years in the Mexican educational system. Since the curricular reform of basic education in 1993, the curriculum has a final goal that is the development of students' competencies. This is due to the consensus among educational authorities that sustainable development and social cohesion fundamentally depend on the competencies of the population (Mexican Ministry of Education, 2017). In fact, the standardized assessment of the National Plan for the Evaluation of Learning in Mexico (PLANEA by its Spanish acronym) aims to evaluate the development of students' competencies (from kindergarten to upper secondary level) in different academic areas, such as language, communication, and mathematics (National Institute for the Evaluation of Education, 2019).

Another reason for adopting this framework is its relation to the notion of mathematical literacy. Through a conceptualization of what it means for a person to be "mathematically competent," this framework offers the construct of mathematical competencies which we found useful for capturing and describing the type of mathematical skills that a citizen in Mexico requires to interpret the official reports on the COVID-19 pandemic.

At the heart of this conceptual framework is the notion of mathematical competence, defined as: 
Someone's insightful readiness to act appropriately in response to all kinds of mathematical challenges pertaining to given situations. It is essential to stress that the 'situations' referred to in this definition need not be mathematical in and of themselves, as long as they (may) generate mathematical challenges. (Niss \& Højgaard, 2019, p. 12 , emphasis in the original text)

However, what we found operationally useful to identify and characterize the necessary mathematical knowledge and skills were the eight constituent components of mathematical competence called mathematical competencies:

A mathematical competency is someone's insightful readiness to act appropriately in response to a specific sort of mathematical challenge in given situations. So, whilst 'mathematical competence' involves the activation of mathematics to deal with all sorts of challenges of a situation or context, 'a mathematical competency' focuses on the activation of mathematics to deal with a specific sort of challenge that actually or potentially calls for 'specific kinds of activation' of mathematics in order to answer questions, solve problems, understand phenomena, relationships or mechanisms, or to take a stance or make a decision. (Niss \& Højgaard, 2019, p. 14, emphasis in the original text)

Next, we make a succinct presentation ${ }^{1}$ of the eight mathematical competencies that constitute the notion of mathematical competence. Although presented separately, these competencies may overlap, depending on the situation and context. After presenting the eight competencies, some related notions that are handy to generate a more precise characterization of the competencies are also introduced.

\subsection{Mathematical thinking competency-engaging in mathematical inquiry ${ }^{2}$}

This competency refers to the ability to "relate to and pose the kinds of generic questions that are characteristic of mathematics and relate to the nature of answers that may be expected to such questions" (Niss \& Højgaard, 2019, p. 15). It involves the ability to distinguish the meaning and role of different types of mathematical statements such as definitions, axioms, conjectures, if-then claims, universal claims, and existence claims.

\subsection{Mathematical problem handling competency—posing and solving mathematical problems}

This competency relates to the ability to pose and solve mathematical problems within and across a variety of mathematical domains. As noted by Niss and Højgaard (2019, p. 15), "a key aspect of this competency is the ability to devise and implement strategies to solve mathematical problems."

\footnotetext{
${ }^{1}$ A more comprehensive account of these theoretical notions can be found in Niss and Højgaard (2011).

2 The names used to refer to the eight mathematical competencies differ between Niss and Højgaard (2011) and Niss and Højgaard (2019). For instance, "Mathematical thinking competency - mastering mathematical modes of thought" in the 2011 publication is "Mathematical thinking competency — engaging in mathematical inquiry" in the 2019 publication. Here we use the names used in the 2019 publication. In subsequent sections of the paper, we use a shortened version of these names.
} 


\subsection{Mathematical modeling competency—analyzing and constructing models of extra-mathematical contexts and situations}

Reference is made here to the ability to build mathematical models, but also to the capability to critically analyze and evaluate existing or proposed models. This competency emphasizes the ability to address extra-mathematical questions, contexts, and situations through mathematical models and modeling.

\subsection{Mathematical reasoning competency-assessing and producing justification of mathematical claims}

This competency includes the ability to "follow and assess mathematic reasoning, i.e. a chain of argument put forward by others, in writing or orally, in support of a claim" (Niss \& Højgaard, 2011, p. 102, emphasis in the original). This competency has to do with mathematical proofs and with the ability to justify mathematical claims, as well as follow and assess the consistency of the mathematical justifications of others.

\subsection{Mathematical representation competency-dealing with different representations of mathematical entities}

This competency has to do with the ability to interpret mathematical information in a variety of representations and to move and translate information between representations. The representation contexts can be graphical, tabular, symbolic, verbal, diagrammatic, etc. The information presented in these contexts can be mathematical objects, phenomena, relationships, and processes.

\subsection{Mathematical symbols and formalism competency-handling mathematical symbols and formalisms}

The ability to understand and deal with mathematical symbols, symbolic expressions and transformations, and the rules and formalisms that govern them, is included in this competency. This competency also includes the ability of "decoding and interpreting instances of symbolic expressions and transformations" (Niss \& Højgaard, 2019, p. 17).

\subsection{Mathematical communication competency_communicating in, with, and about mathematics}

Mathematical communication can take place through different means of communication (written, oral, gestural), but it can also manifest itself in different genres and styles and with varied levels of technical and conceptual depth. The ability to interpret the mathematical communication of others, and to perform as an active mathematical communicator, is included in this competency.

\subsection{Mathematical aids and tools competency—handling material aids and tools for mathematical activity}

In this competency, reference is made to the ability to put into productive use material aids and tools as part of the mathematical activity. Such material aids and tools may vary: blocks, rulers, abacuses, calculators, software, mobile devices, etc. 
After this brief presentation of the eight constituents of mathematical competence, some complementary notions that are useful in producing a more accurate characterization of mathematical competencies are now introduced.

\subsection{Facets and dimensions of a mathematical competency}

All mathematical competencies are manifested either in a receptive facet or in a constructive facet. According to Niss and Højgaard (2019), in the receptive facet of a competency, the individual manifests the ability to "relate to and navigate with respect to considerations and processes which have already been introduced (typically by others) into a given context or situation" (p. 19), while in the constructive facet, "the focus is on the individual's ability to independently invoke and activate the competency to put it to use for constructive purposes in given contexts and situations" (p. 19).

On the other hand, individuals' mathematical competence manifests in different contexts and situations but never in its full range, that is, it is not possible to exhaustively and completely possess a mathematical competency. For this reason, there are three dimensions that allow definition and characterization of the degree of possession of a competency by an individual: degree of coverage, radius of action, and technical level. In this study, these dimensions are used to produce a more detailed characterization of the mathematical competencies required to interpret official information on the COVID-19 pandemic. The three dimensions are defined as follows:

The degree of coverage of a competency is the extent to which all the aspects that define and characterise the competency form part of that individual's possession of the competency. [...] The radius of action represents the range and variety of different contexts and situations in which the individual can successfully activate the competency. [...] [The technical level] denotes the level and degree of sophistication of the mathematical concepts, results, theories and methods which the individual can bring to bear when exercising the competency. (Niss \& Højgaard, 2019, p. 21)

\section{Research question}

Now that we have presented the framework of mathematical competencies and the context of study, we formulate in more precise terms the research question that guides this study:

What are the mathematical competencies that a citizen requires to interpret Mexico's official information on the COVID-19 pandemic?

We approach this question from the perspective of the context that we have previously described. To answer it, we conducted an analysis of the technical reports included in the daily reports of the Mexican Ministry of Health, using the framework of mathematical competencies as a lens. The next section explains how these notions were operationalized in the analysis of selected video recordings. 


\section{Analysis of the daily reports on the COVID-19 pandemic}

From February 29, 2020 (the day when the first daily report was transmitted), to May 31, 2020 (the day the first version of this paper was submitted), a total of 101 reports were transmitted to the Mexican population. These reports are stored on the YouTube channel of the Mexican Ministry of Health after being broadcast live and can also be accessed through the website https://www.gob.mx/..$^{3}$

This study is based on the analysis of 25 selected video recordings of these reports (see electronic supplementary material). The selection and analysis of these reports was carried out gradually by applying the following procedure: on March 25, 2020, the report transmitted on February 29, 2020, was selected and analyzed. This report was selected as it was the first to be broadcast to the public and the only one that was transmitted during that month. With the help of an online random number generator, on April 1, 2020, eight reports transmitted during the month of March 2020 were randomly selected and analyzed during the subsequent days. Following a similar process, on May 2, 2020, eight reports transmitted during the month of April 2020 were randomly selected to analyze them during the following days. Finally, on May 28, 2020, eight reports transmitted during May 2020 were randomly selected and analyzed during the last days of May 2020.

The analysis focused on the initial section of the reports called "technical report." As mentioned before, this section of the daily reports lasts around $20 \mathrm{~min}$ and includes figures, percentages, graphs, and other mathematical and statistical information whose role is to illustrate the degree of development of the pandemic in Mexico and around the globe. This information is presented through a slide deck but also verbally. An example of a daily report can be found at https://youtu.be/MhV2rl5v7i0 (last time accessed May 31, 2020). This daily report corresponds to April 15, 2020, and the technical report of this transmission is located between the time codes 3:16 and 28:13 of the video.

\subsection{Application of the mathematical competency framework}

The application of the framework of mathematical competencies to the analysis of the daily reports was divided into two stages. The two authors of this study participated in the development of the two stages, which are described below.

Stage 1 In the first stage, we began by familiarizing ourselves with the content of the technical reports, watching them all, and identifying instances in which mathematical content appeared. The mathematical content appears mostly in the slide deck, but it was also expressed verbally.

Next, an investigator triangulation (Rothbauer, 2008) was implemented: each researcher independently identified which mathematical competencies would be necessary to interpret the information reported in each of the technical reports. Later, we discussed our findings over Skype meetings, trying to reach a consensus on the interpretation of the data. There was not much room for discrepancies, because the mathematical competencies required to interpret the technical reports were relatively easy to identify. In fact, we reached a point of "theoretical

\footnotetext{
${ }^{3}$ According to the Government of Mexico (n.d.), the information contained in this website is public (including the YouTube videos). The user who reproduces or processes information contained on the website must mention its electronic location and the date on which the information was consulted. Such information is included in the electronic supplementary material of this paper.
} 
saturation" during this stage of the analysis, in the sense that the examination of new videos did not lead to the identification of new necessary competencies.

Stage 2 In this second stage, we focused on producing a more detailed characterization of the mathematical competencies identified during the first stage of the analysis. For this, we made use of the dimensions to define and characterize the degree of possession of a competency: degree of coverage, radius of action, and technical level.

As pointed out by Niss and Højgaard (2019, p. 22), these dimensions are "meant to be of a qualitative nature, where each of them represents a partial ordering of competency possession: 'more (or less) than . . . with respect to . ...' Operationalizing these dimensions in the data analysis was one of the challenges we encountered when adapting the framework of mathematical competencies to the analysis of the daily reports. It was necessary, particularly for the dimensions of the radius of action and technical level, to build a reference point to carry out the ordering of the competency requirement.

To operationalize the three dimensions, we used a basic classification (low, medium, and high) with respect to different reference points. In the case of the degree of coverage, it was decided whether it was low or high depending on to what extent all the aspects that define and characterize a competency were required. It was considered high if all the aspects considered within the competency — as defined by Niss and Højgaard (2019, 2011) — were required. If all aspects of a competency were not required, then it was agreed through the triangulation process whether the dimension was considered low or medium. For the dimensions radius of action and technical level, the Mexican curriculum was used as a reference: these dimensions were considered to be at a low level if the range and variety of different contexts in which the competency should be activated or the level and degree of sophistication of the mathematical concepts involved in the interpretation of the information correspond to the thematic contents expected to be covered in the basic or lower secondary level in Mexico. The dimensions were considered to be at a high level when the contexts and degrees of sophistication correspond to the thematic contents that should be covered at the upper secondary or university level. The grade medium was assigned to those episodes where the researchers considered that the low and high ratings failed to adequately capture the dimension of competency.

The two stages of the analysis were applied to the technical reports of the 25 randomly selected video recordings. The results of this analysis were concentrated in a spreadsheet to construct an overview of the mathematical competencies required to interpret the technical reports. The competencies required to interpret each of the 25 technical reports were registered in this spreadsheet, as well as the maximum value of their corresponding dimensions.

\section{Illustration of the data analysis process}

To provide a clearer idea of the content of the technical reports and the way it was analyzed using the framework of mathematical competencies, an episode of the technical report corresponding to April 15, 2020 (see https:/youtu.be/MhV2rl5v7i0), is described and analyzed below. What the presenter says is transcribed, and the slide that the presenter uses as support while speaking is shown. Transcripts are presented in Spanish-the original language of the presentation-followed by an English translation. 
We have selected this video and this particular episode because they are representative of the type of information that is communicated through the technical reports. Episode 1 (time codes 12:16-12:28 + 14:07-14:36) presented below was located as part of the stage 1 of the data analysis.

In Episode 1, the presenter asks to project the slide shown in Fig. 1. The title of the slide reads "COVID-19: Distribution of confirmed cases by type of patient and age group 15/04/ 2020." The slide shows a bar chart where the vertical axis represents the number of confirmed cases (CASOS) and the horizontal axis shows different intervals that represent age groups (GRUPO DE EDAD). The slide also shows a pie chart in the upper right corner, which represents the distribution of confirmed cases according to the gender (SEXO) of the patients, male or female (Hombres, Mujeres).

The presenter continues by introducing the meaning of the green and yellow bars:

Aquí lo que vemos y nos interesa siempre destacarlo, es la distribución de casos graves que están en las barras amarillas con casos leves que están en las barras verdes [...]

Here what we see and we are always interested in highlighting it, is the distribution of severe cases that are in the yellow bars with mild cases that are in the green bars [...]

Here the presenter leaves the slide for a moment to refer to a recently implemented epidemiological surveillance program. At time 14:07, he returns to the slide and explains:

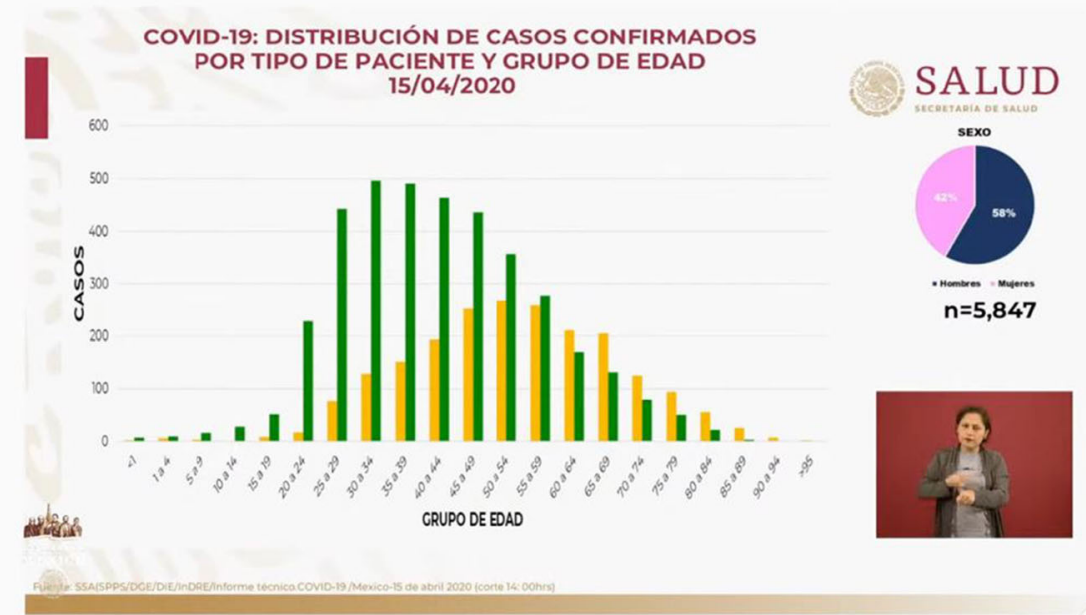

Fig. 1 This slide shows a bar chart with two groups of data representing the distribution of confirmed cases of COVID-19 by type of patient (severe and mild cases) and age group. The slide also shows a related pie chart representing the distribution of confirmed cases according to the gender of the patients 
[...] pero aquí la señal importante es ver cómo en el adulto joven tenemos un predominio de los casos leves [En este momento el presentador representa a través de gesticulaciones un intervalo cuyos puntos extremos son también intervalos. Aparentemente lo hace para indicar qué quiere decir al referirse a 'adulto joven'. Primero señala con su mano el intervalo que va de 55 a 59, y después desliza su mano sobre el eje horizontal para señalar el intervalo que va de 25 a 29], pero en cambio en adulto mayor de 60 años las barras amarillas superan a las barras verdes [Aquí se señala otro intervalo para indicar dónde se localizan en la gráfica los adultos mayores a 60 años. El presentador señala primero con su dedo índice el intervalo que va de 60 a 64, y después lo desliza sobre el eje horizontal terminando su movimiento en un punto adyacente al intervalo que va de 75 a 79]. Esto quiere decir tenemos una mayor frecuencia de casos graves comparado con casos leves, aunque también existen casos leves en adultos mayores.

[...] But here the important signal is to see how in young adults we have a predominance of mild cases [At this moment the presenter represents through gestures an interval whose endpoints are also intervals. Apparently to indicate what he means by 'young adults'. He first points to the interval 55 to 59 with his hand, and then slides the hand over the horizontal axis to point to the interval 25 to 29], but on the other hand, in adults older than 60 years the yellow bars exceed the green bars [Here another interval is pointed out to indicate where the adults older than 60 years are located in the graph. First the presenter points with his index finger to the interval 60 to 64 and then slides it along the horizontal axis ending his movement at a point next to the interval 75 to 79]. This means we have a higher frequency of severe cases compared to mild cases, although there are also mild cases in older adults.

The first stage of our analysis consists of identifying instances within the technical report in which the mathematical content is present. Episode 1 is a typical example of those instances. The first stage of the analysis continues by identifying and agreeing among the researchers the mathematical competencies that would be necessary to interpret the information contained in these instances. In this case, it was concluded that the necessary competencies for the interpretation of Episode 1 are mathematical communication, mathematical modeling, mathematical representation, and mathematical symbols and formalism. The rationale for this interpretation is presented next.

\subsection{Mathematical communication competency}

This competency is necessary because Episode 1 requires the ability from the viewer to interpret the mathematical communication of others - in this case the presenter - through graphic, oral, and gestural means of communication.

\subsection{Mathematical modeling competency}

Episode 1 is developed around a statistical model that represents the distribution of confirmed cases of COVID-19 by type of patient, age group, and gender (Fig. 1). Thus, the ability to interpret a model proposed by others is required in this episode. 


\subsection{Mathematical representation competency}

It is argued that this competency is necessary because the mathematical information presented in Episode 1 requires that the viewer be able to interpret and connect different representations such as bar graphs and pie graphs.

\subsection{Mathematical symbols and formalism competency}

Episode 1 involves mathematical symbolic expressions that must be interpreted by the viewer of the technical report. Here we refer to the mathematical symbols that appear in Fig. 1 such as numbers, $\%, \mathrm{n},=,<$, and $>$.

Now the second stage of the analysis begins. Here, a more detailed characterization of the required mathematical competencies is produced. For this, the dimensions that define and characterize the degree of possession of a competency are put into operation: degree of coverage, radius of action, and technical level. Due to space limitations, in the following we explain our reasoning to determine the dimensions of two of these competencies.

\subsection{Mathematical communication competency}

Degree of coverage (medium). The mathematical communication competency comprises the ability to interpret the mathematical communication of others but also perform as an active mathematical communicator. Because Episode 1 only requires interpreting the mathematical communication of others, this dimension was not considered as high. However, it was not considered as low either because Episode 1 requires the viewer to interpret a mathematical communication that takes place in different contexts of representation (graphical, oral, gestural), which she or he must coordinate. For example, the viewer needs to associate the presenter's gestures when he represents intervals with his hand with the oral and graphic information received. Thus, the level of this dimension was qualified as medium.

Radius of action (high). The radius of action represents the range and variety of different contexts and situations in which the individual should successfully activate the competency. In the case of Episode 1, the mathematical information that the viewer must interpret is embedded in a medical context in which the distribution of confirmed cases of an infectious disease among different groups of people must be interpreted. This is not the type of context that would be commonly used to contextualize mathematical problems or tasks in the basic levels of instruction in Mexico. It is a context more likely to be found in more advanced degrees of mathematical instruction. For this reason, this dimension was classified as high.

Technical level (high). This dimension refers to the degree of sophistication of the mathematical concepts necessary to exercise this competency. Although most of the mathematical concepts involved in the presenter's communication are covered in the basic levels of instruction in Mexico (e.g., bar charts, pie charts, percentage, frequency, inequality), this dimension was not classified as low. This is because Episode 1 requires the spectator to coordinate all these mathematical concepts as part of the same message. 
For example, it is necessary to coordinate the information from two COVID-19 case distributions (represented by the green and yellow bars) and associate them with the gender distribution represented by the percentages within the pie chart. This mathematical information in turn must be related to the speaker's spoken speech. We consider that these mathematical requirements to interpret Episode 1 exceed those expected from basic education for children in Mexico. For this reason, we categorize the dimension as high.

\subsection{Mathematical symbols and formalism competency}

Degree of coverage (low). This competence refers to the ability to understand and deal with mathematical symbols, symbolic expressions, and transformations and the rules and formalisms that govern them. Episode 1 requires the viewer to decode and interpret instances of symbolic expressions; however, it does not require the viewer to perform symbolic transformations nor apply transformation rules. This dimension was rated as low.

Radius of action (medium). The mathematical symbols that appear in Episode 1 as \%, $\mathrm{n}$, $<$, and $>$ are usually studied at the basic level of mathematical instruction in Mexico. However, students come across these symbols primarily in purely arithmetic or algebraic contexts. That is, Episode 1 requires the spectator to identify mathematical symbols but interpret them in an extra-mathematical context. We think that this interpretive requirement of the symbols is not basic, so this dimension was qualified as medium.

Technical level (medium). The degree of sophistication of the mathematical symbols required to interpret Episode 1 could be considered basic. However, this dimension was not classified as low. This is because these "basic" symbols must be interpreted by the viewer within a context that assigns them a particular meaning. Episode 1 requires not only that the viewer recognize and understand the mathematical symbols involved. It also requires the viewer to assign them a meaning associated with a particular context. This dimension was classified as medium.

\section{Results}

Although the data analysis was discrete - one technical report at a time - the results should be interpreted globally. The spreadsheet on which the results of the analysis were concentrated was instrumental for such a global interpretation. The overview of the data analysis represented in the spreadsheet provides a clear picture of the competencies required to interpret the selected technical reports. According to our analyses, the interpretation of each of the 25 technical reports requires the viewer to put into operation mainly five mathematical competencies: mathematical communication, mathematical representation, mathematical symbols and formalism, mathematical modeling, and mathematical reasoning competency.

We claim that mainly these five competencies are required, because all of them were identified as needed to interpret each of the 25 selected technical reports. However, in the technical report for April 21, 2020, there is an episode when the presenter uses in his explanation a biconditional logical connective between statements: 
Decidimos con base en las recomendaciones de los grupos científicos. Siete grupos académicos que coordinó CONACYT, especialistas en matemáticas, algunos específicamente en epidemiología matemática. Coincidieron en una predicción de lo que está ocurriendo en México y podría continuar ocurriendo si y solo si la jornada nacional de sana distancia, es decir quédate en casa, se cumple apropiadamente.

We made the decision following recommendations from the scientific groups. Seven academic groups coordinated by CONACYT ${ }^{4}$, specialists in mathematics, some of them specifically in mathematical epidemiology. They agreed on a prediction of what is happening in Mexico and could continue to happen if and only if the national campaign of healthy distancing, that is stay at home, is properly fulfilled. (Technical report, April 21, 2020, 47:29)

It could be argued that the interpretation of this utterance requires the viewer to put into play the mathematical thinking competency, that is, the ability to distinguish the meaning and role of different types of mathematical statements - in this case the expression "if and only if." However, this was the only instance in which the need to exercise this competency was identified.

The competencies identified as necessary are required in their receptive facet. This means that the citizen who is the recipient of the daily reports would need to activate these mathematical competencies in a "passive" role in which a series of data and mathematical representations that have been elaborated by others must be interpreted and given meaning.

In what follows, we elaborate on the five main competencies that are required to interpret the technical reports on the COVID-19 pandemic in Mexico. A global interpretation of the required competencies and their dimensions is provided.

\subsection{Mathematical communication competency}

This is one of the competencies whose indispensableness for the interpretation of the technical reports is more evident. The technical reports of the Mexican Ministry of Health are an instance of mathematical communication in which one or several health officials deliver a message based on mathematical entities and relationships, which the citizen is expected to be able to decode. As has been illustrated in Episode 1, this mathematical communication takes place in gestural, oral, and visual registers.

The degree of coverage for this competence is considered as medium because the individual does not need to be an active and constructive communicator but only needs to interpret the mathematical communication of others. However, the technical reports require the viewer to interpret a mathematical communication that takes place in different contexts of representation. The radius of action is regarded as high because the contexts and registers where this competency needs to be activated are not common to the basic mathematical instruction in Mexico but more typical of higher levels of instruction. The technical level of this competency is linked to the technical levels of the rest of the competencies, which are generally high. In other words, the interpretation of the mathematical communication that takes place in the

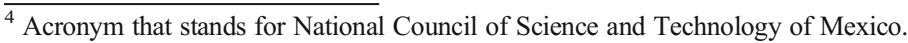


technical reports involves the understanding and coordination of a wide variety of mathematical concepts that go beyond basic instruction, which leads us to rate it as high.

\subsection{Mathematical representation competency}

Compared to the rest of the required competencies, this is the mathematical competency that is required in the most robust form. This is because the technical reports make abundant use of different types of mathematical representations, many of them with a level of sophistication that is not basic.

The degree of coverage of this competency is high because the observer is required to interpret and move between a wide range of representations. The technical reports display mathematical and statistical information verbally, symbolically, tabularly, graphically, and diagrammatically. An instance of tabular information is found in Fig. 2, which represents the fatality rate by case condition.

The radius of action for this competency is also high because the representations that the individual must be able to interpret refer to a variety of situations and contexts that go beyond basic education in Mexico, for instance, availability of beds in hospitals, confirmed and active cases of COVID-19, people's mobility, and some notions of epidemiology such as the positivity rate of a virus. The dimension of technical level is high because the individual is required to handle a wide variety of graphic representations, several of them corresponding to thematic contents of upper secondary and university level. For example, different types of statistical graphs are deployed (bar charts, pie charts, line graphs) but also Cartesian graphs and

\section{COVID-19 México: Letalidad por condición de caso}

\section{1 mayo, 2020}

\begin{tabular}{|lccc|}
\hline Condición de caso & Casos & Defunciones & Letalidad (\%) \\
\hline Ambulatorio & 21,898 & 344 & 1.6 \\
\hline Hosp. Estable & 4,684 & 707 & 15 \\
\hline Hosp. Grave & 8,279 & 1,705 & 21 \\
\hline Hosp. Intubados & 1,466 & 817 & 56 \\
\hline Total & $\mathbf{3 6 , 3 2 7}$ & $\mathbf{3 , 5 7 3}$ & $\mathbf{9 . 8}$ \\
\hline
\end{tabular}

\begin{tabular}{|l|l|}
\hline Hosp. Estable & $\begin{array}{l}\text { Paciente hospitalizado que no cumpla con ninguno de los dos criterios } \\
\text { siguientes }\end{array}$ \\
\hline Hosp. Graves & $\begin{array}{l}\text { Paciente hospitalizado positivo, que tenga o haya tenido neumonia o que este } \\
\text { ohaya estado en la UCI }\end{array}$ \\
\hline Hosp. Intubados & Paciente hospitalizado positivo y que haya sido intubado \\
\hline
\end{tabular}

Fig. 2 Data table representing the fatality rate by case condition: Outpatient (Ambulatorio), Hospitalized Stable (Hosp. Estable), Hospitalized Critical (Hosp. Grave), and Hospitalized Intubated (Hosp. Intubados). The columns represent the case condition (Condición de caso), the number of cases (Casos), the number of deaths (Defunciones), and the fatality rate (Letalidad \%) 


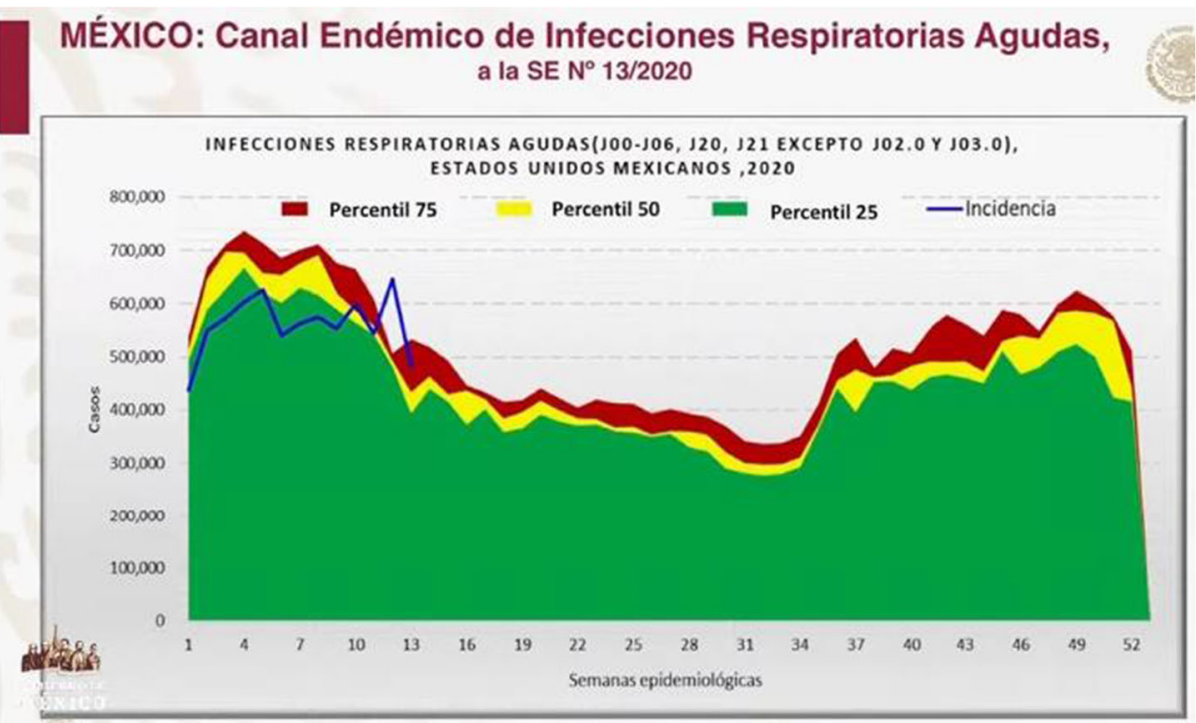

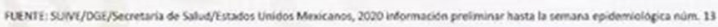

Fig. 3 Endemic channel of acute respiratory infections in Mexico for the year 2020. An endemic channel represents the number of cases within the expected normal seasonal range; anything above this moving threshold would be considered representative of an unprecedented number of cases, that is, an outbreak.

even graphs specific to epidemiology, such as the endemic channel for acute respiratory infections in Mexico (see Fig. 3).

\subsection{Mathematical symbols and formalism competency}

The technical reports require the viewer to know some basic mathematical symbols and to handle certain types of numbers such as natural, decimal, and negative. However, these mathematical symbols must be interpreted by the spectator within a range of contexts that assign them a particular meaning.

The degree of coverage is considered low since, although knowledge of some mathematical symbols that appear in the reports is required, these symbols are basic. In addition, no knowledge is required to operate them nor is knowledge of theoretical frameworks (formalisms) required. There are several contexts in which mathematical symbols appear, representing different information in each situation. Most of these contexts do not correspond to those that one would find in elementary mathematical education in Mexico. This is why the dimension radius of action is considered high. The technical level of this competency is considered to be high because, even though the degree of sophistication of the mathematical symbols present in the technical reports may be basic, such symbols must be interpreted by the viewer within a variety of contexts that assigns them a particular meaning.

\subsection{Mathematical modeling competency}

The technical reports include different mathematical models, usually graphically represented, that the viewer must be able to interpret. Here, the mathematical modeling competency is indispensable to carry out such interpretation. 


\section{COVID-19 México: Proyección y observación de casos confirmados}

\section{Valle de México al 10 mayo, 2020}

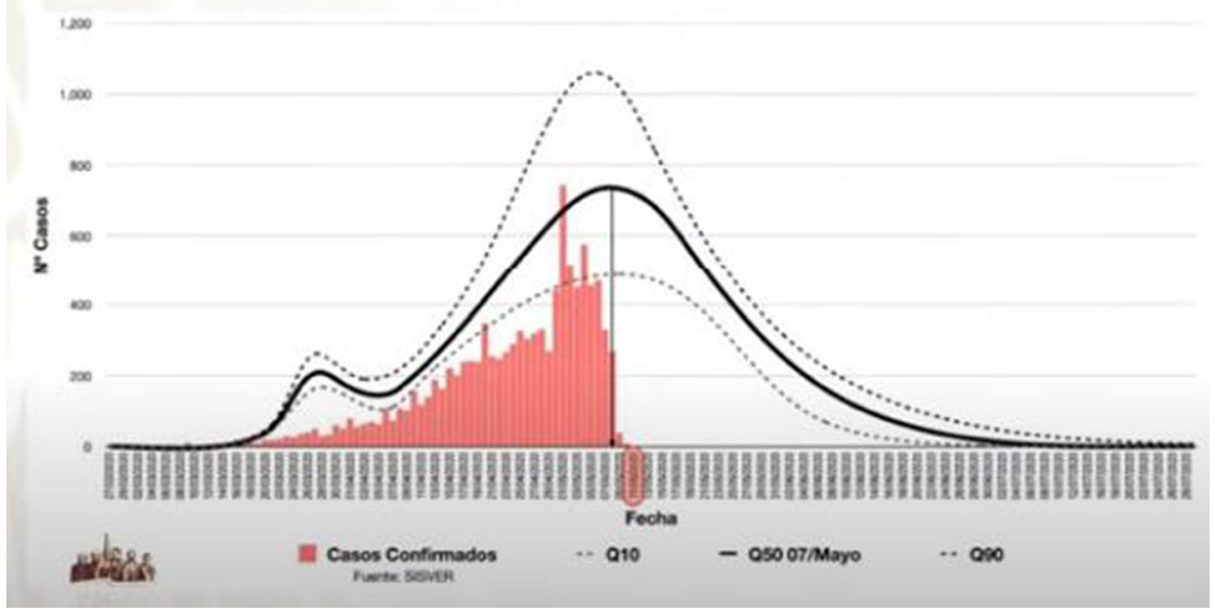

Fig. 4 A mathematical model that estimates the number of confirmed cases of COVID-19 in Mexico City and its metropolitan area under different hypothetical scenarios. The title of the slide reads "COVID-19 Mexico: Projection and Observation of Confirmed Cases. Valley of Mexico as of May 10, 2020"

The degree of coverage of this competence is not high because the individual is not required to construct mathematical models on their own but rather to analyze and evaluate the mathematical models that have been developed by others. However, it is necessary for the viewer to interpret and analyze mathematical models embedded in a wide variety of extramathematical contexts. Thus, this dimension is considered as medium. As mentioned, there are varied contexts and situations associated with the evolution of the pandemic in Mexico in which mathematical models are used: to predict the number of patients who will be simultaneously intubated, to predict the behavior of infections in the country and its main cities, to estimate the mobility of people, to compare the positivity rate of different viral diseases, etc. Such contexts go beyond the type of contexts that are usually used in the basic instruction in Mexico. Thus, the radius of action of this competency is considered to be high. For similar reasons, the technical level is also considered high. The viewer of the daily reports must be able to interpret various mathematical models, which are displayed through different graphic representations, based on different data and assumptions, and generate different predictions that can be compared with the observed data. An example is shown in Fig. 4, which shows a mathematical model that estimates the number of confirmed cases of COVID-19 in Mexico City and its metropolitan area under different hypothetical scenarios, compared with the observed data. The title of the slide reads "COVID-19 Mexico: Projection and observation of confirmed cases. Valley of Mexico as of May 10, 2020.”

\subsection{Mathematical reasoning competency}

All technical reports contain episodes in which the viewer must follow and interpret arguments, explanations, and statements of the presenter that are based on mathematical 
information. One could even argue that the presenter's speech in Episode 1 is an instance of those kinds of explanations. An example illustrating the need for the mathematical reasoning competency to follow the presenter's explanations is illustrated in the following transcript. Here, the presenter introduces the audience to the concept of "positivity rate." His speech is associated with the slide shown in Fig. 5 whose title reads "COVID-19: positivity rate for viral disease 15/04/2020." The horizontal axis indicates the epidemiological week number (SEMANA EPIDEMIOLÓGICA), and the vertical axis indicates the positivity index (\% Positividad). The gray and red line graphs represent the positivity rate for influenza and COVID-19, respectively.

Este es el famoso porcentaje de positividad. Quiere decir: de cada 100 personas que tienen fiebre, dolor de cabeza, dolor de garganta y uno de los otros síntomas, y se les toma una muestra para identificar si tienen o no infección por el nuevo coronavirus SARS-CoV-2, 13.3 por ciento se encuentra que lo tiene [el presentador termina esta frase señalando con su dedo índice el valor 13.30 en la gráfica de color rojo].

This is the famous positivity rate. It means: of every 100 people who have a fever, headache, sore throat and one of the other symptoms, and a sample is taken to identify whether or not they have infection with the new coronavirus SARS-CoV-2, 13.3 percent is found to have it [the presenter ends this sentence by pointing with his index finger at the value 13.30 on the red line graph]. (Technical report, April 15, 2020, 25:19)

The transcript above shows an explanation from the presenter that the audience should follow and interpret. Particularly, the audience must grasp the meaning of the value 13.30 located in the red line graph that represents the positivity rate for COVID-19 during week number 16 . The presenter indicates that a sample should be taken from the symptomatic person to determine the positivity

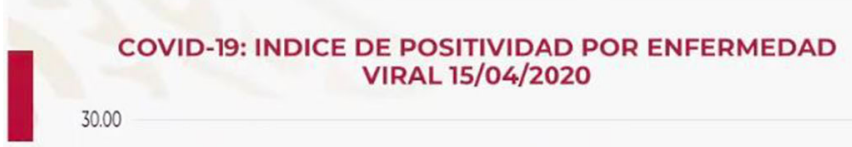

\section{SALUD}

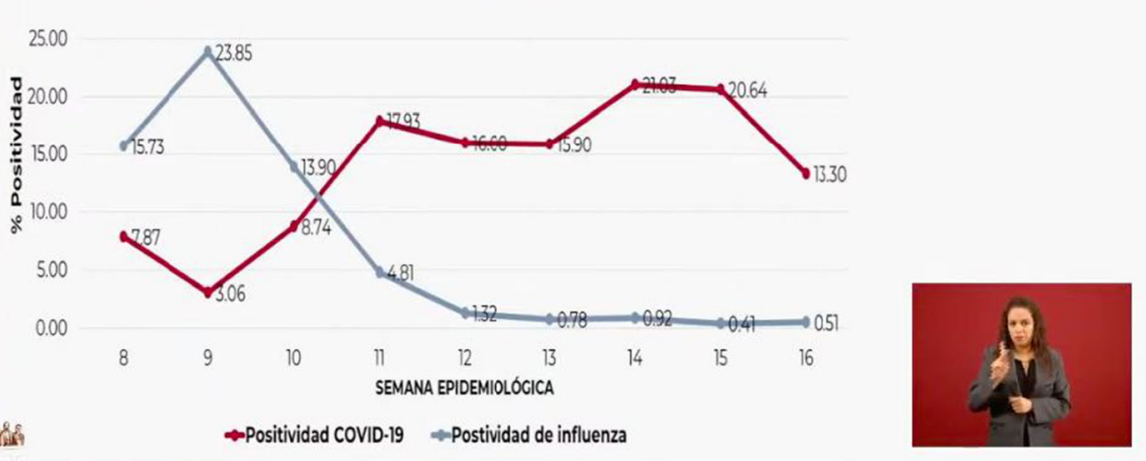

Fig. 5 Line graphs representing the positivity rate for influenza (gray graph) and COVID-19 (red graph) diseases. The title reads "COVID-19: positivity rate for Viral Disease 15/04/2020" 
rate. This condition could inform the viewer exercising a mathematical reasoning competency that the positivity rate is an indicator that depends on the testing capacity of the country.

The degree of coverage of this competency was not classified as high because the aspects of the competency related to the construction and assessment of mathematical proofs are not required to interpret the technical reports. However, because the ability to follow arguments, explanations, and statements is widely needed to interpret the technical reports, this dimension was classified as medium. The radius of action of this competency is considered to be high because the arguments and explanations put forward by the presenter are based on a wide variety of contexts. These contexts, as illustrated in Fig. 5, are not common to basic mathematical instruction in Mexico. Similarly, the technical level required to interpret technical reports is considered high. This is because the explanations and arguments presented in the reports are based on different concepts and mathematical representations that must be coordinated by the viewer. The variety of concepts and representations used in the arguments and explanations presented exceed those covered in the basic levels of instruction in Mexico.

\section{Discussion}

The daily reports issued by the Mexican Ministry of Health represent an unprecedented event for this country. Never before in Mexico have mathematics and mathematicians had a media projection like the one these reports have provided them. On a daily basis and for months, reports have been transmitted in which mathematical concepts and epidemiological concepts are intertwined and in which the work of Mexican mathematicians in containing the pandemic is constantly recognized.

This is an opportunity to learn. The international community interested in mathematical literacy studies could learn from the Mexican experience or from similar research done elsewhere. As pointed out by Niss and Jablonka (2014) in connection to the notion of mathematical literacy, "there is no general agreement amongst mathematics educators as to the type of contexts with which a mathematically literate citizen will or should engage and to what ends" (p. 394). The study reported in this article may provide a glimpse into the kind of mathematical competencies useful to an adult citizen in the context of a viral pandemic. Similar studies in other regions of the world could provide us with a clearer picture of the type of mathematical knowledge and skills that citizens require to navigate this type of emergency health situation.

The mathematical competencies that would be necessary to fully interpret the technical reports issued by the Mexican Ministry of Health were identified in this study. Although competencies are addressed separately in the data analysis and results, in practice these competencies overlap. We believe that Episode 1 illustrates the intertwined nature of mathematical competencies in practice. For instance, it would not be possible to interpret the model represented in Fig. 1 through the exercise of mathematical modeling competency without also activating the mathematical representation competency.

The study suggests that two mathematical competencies would not be required to interpret these technical reports: the mathematical problem handling competency and the mathematical aids and tools competency. No instances were found in which the interpretation of an episode explicitly required formulating and solving mathematical problems or using any aid or tool. However, it is fair to assume that some viewers could use a tool-such as a mobile phone calculator - to follow the mathematical information presented in the technical reports. Corroborating this assumption is of course beyond the scope of our method of inquiry. 
Our approach to the question about the type of mathematical knowledge that an ordinary citizen would need in order to interpret the official information about the coronavirus pandemic is based in the application of the framework of mathematical competencies. But there must be other approaches to the question. The technical reports contain several episodes related to statistical concepts very similar to Episode 1. It is possible to notice that concepts such as frequency, distribution, bar chart, and pie chart appear both in the slide shown in Fig. 1 and in the presenter's oral speech. It is therefore pertinent to think about the use of theoretical approaches organized around the notion of statistical literacy to address this same question (Engel, 2019; Gal, 2002; Watson \& Callingham, 2003).

We also acknowledge that the kind of mathematical competencies in their receptive facet that were identified as necessary to interpret the reports considered in this study could also be present in other types of reports transmitted through radio, TV, or Internet in other regions of the world. This would imply not only that our approach to the analysis of media reports could also be applied in other contexts but should also be interpreted as an invitation to reconsider our ideas about what should be the basic mathematics necessary to equip literate citizens in contemporary societies.

Returning to the particular case of Mexico and the daily reports issued by its Ministry of Health, we assume that the government transmits them hoping that the Mexican population can interpret them, but does this really happen?

This study shows that the majority of the radius of action and technical level dimensions of the competencies required to interpret the daily reports are high. This means that they correspond to thematic content at the upper secondary level and undergraduate level. However, there are reports that confirm that not all of the Mexican population has access to those educational levels (e.g., OECD, 2019); in addition, recent results of the national standardized test that evaluates mathematical knowledge and skills shows that Mexican students at the lower secondary level have difficulties with basic components of some of the competencies identified, such as reading information contained in tables and graphs (National Institute for the Evaluation of Education, 2019). What we want to argue here is that there is a significant portion of the Mexican population that does not have the necessary mathematical competencies to decipher and interpret the reports issued by the Mexican Ministry of Health. What are the consequences of this exclusion?

One of the most immediate consequences is the risk to individual and collective health. The development of health numeracy has a direct relationship with the well-being of people, since it allows them to interpret health information expressed in mathematical terms and make appropriate health decisions (e.g., interpreting medication doses or extracting health-related information from food packaging). However, a population with poorly developed health numeracy could represent a potential threat to public health, particularly in situations like this pandemic that we are experiencing. For instance, there are studies showing that people with robust statistical literacy are more likely to support COVID-19 prevention measures such as social distancing (Lammers et al., 2020). As noted by Levy et al. (2014), "individuals with low numeracy, compared with those who have higher numeracy, are less likely to understand health risk or to comply with medications regimes, are known to underuse screening for colorectal cancer, have greater difficulty managing chronic conditions, and report worse subjective health" (p. 107).

We close this paper by sharing some open questions about mathematics and mathematics education and hoping that this article and this special issue will spark many other questions and reflections: 
This phenomenon of lack of access to medical information connected to the possession of mathematical competencies becomes especially relevant in this pandemic scenario. It is a phenomenon that invites us to reflect as mathematics educators.

- How does the mathematical curriculum of our nations prepare-or fail to preparecitizens for a global crisis like the one we are experiencing?

- What is the role of mathematics and mathematics education in a post-pandemic world?

- How can we exploit the didactic potential of official communications such as daily reports in Mexico or elsewhere to illustrate to our students the function of mathematics in socially relevant situations?

Supplementary Information The online version contains supplementary material available at https://doi.org/ 10.1007/s10649-021-10082-9.

\section{References}

Askew, M., Brown, M., Rhodes, V., Wiliam, D., \& Johnson, D. (1997). The contribution of professional development to effectiveness in the teaching of numeracy. Teacher Development, 1(3), 335-356. https://doi. org/10.1080/13664539700200030

Australian Association of Mathematics Teachers. (1997). Numeracy = everyone's business. In The report of the numeracy education strategy development conference. Commonwealth of Australia.

Brown, M., Askew, M., Baker, D., Denvir, H., \& Millett, A. (1998). Is the national numeracy strategy researchbased? British Journal of Educational Studies, 46(4), 362-385. https://doi.org/10.1111/1467-8527.00090

Coben, D., \& O’Donoghue, J. (2014). Adults learning mathematics. In S. Lerman (Ed.), Encyclopedia of mathematics education (pp. 15-23). Springer. https://doi.org/10.1007/978-94-007-4978-8 5

Engel, J. (2019). Statistical literacy and society: What is civic statistics? In J. M. Contreras, M. M. Gea, M. M. López-Martín, \& E. Molina-Portillo (Eds.), Actas del tercer congreso internacional virtual de educación estadistica [Proceedings of the third international virtual congress on statistics education] (pp. 1-17). University of Granada. https://digibug.ugr.es/bitstream/handle/10481/55027/engel.pdf

Frankenstein, M. (1990). Incorporating race, gender, and class issues into a critical mathematical literacy curriculum. Journal of Negro Education, 59(3), 336-347. https://doi.org/10.2307/2295568

Gal, I. (2002). Adults' statistical literacy: Meanings, components, responsibilities. International Statistical Review, 70(1), 1-51. https://doi.org/10.1111/j.1751-5823.2002.tb00336.x

Gigerenzer, G., \& Edwards, A. (2003). Simple tools for understanding risks: From innumeracy to insight. $B M J$, 327, 741-744. https://doi.org/10.1136/bmj.327.7417.741

Golbeck, A. L., Ahlers-Schmidt, C. R., Paschal, A. M., \& Dismuke, E. (2005). A definition and operational framework for health numeracy. American Journal of Preventive Medicine, 29(4), 375-376. https://doi.org/ 10.1016/j.amepre.2005.06.012

Government of Mexico (n.d.). Términos y condiciones de uso de gob.mx [Terms and conditions of use of gob.mx]. https://www.gob.mx/terminos

Heilmann, L. (2020). Health and numeracy: The role of numeracy skills in health satisfaction and health-related behaviour. ZDM-Mathematics Education, 52(3), 407-418. https://doi.org/10.1007/s11858-019-01106-z

Lammers, J., Crusius, J., \& Gast, A. (2020). Correcting misperceptions of exponential coronavirus growth increases support for social distancing. Proceedings of the National Academy of Sciences of the United States of America, 117(28), 16264-16266. https://doi.org/10.1073/pnas.2006048117

Levy, H., Ubel, P. A., Dillard, A. J., Weir, D. R., \& Fagerlin, A. (2014). Health numeracy: The importance of domain in assessing numeracy. Medical Decision Making, 34(1), 107-115. https://doi.org/10.1177/ 0272989X13493144

Mexican Ministry of Education (2017). Aprendizajes clave para la educación integral [Key learnings for comprehensive education]. https://www.planyprogramasdestudio.sep.gob.mx/descargables/ APRENDIZAJES_CLAVE_PARA_LA_EDUCACION_INTEGRAL.pdf 
National Institute for the Evaluation of Education (2019). Informe de resultados PLANEA 2017. El aprendizaje de los alumnos de tercero de secundaria en México. Lenguaje y comunicación y matemáticas [Report of the PLANEA results 2017. The learning of third-year lower secondary school students in Mexico. Language and communication and mathematics]. https:/historico.mejoredu.gob.mx/wp-content/uploads/2019/08/P1D321. pdf

Niss, M. (2003). Quantitative literacy and mathematical competencies. In B. L. Madison \& L. A. Steen (Eds.), Quantitative literacy: Why numeracy matters for schools and colleges (pp. 215-220). National Council on Education and the Disciplines.

Niss, M., \& Højgaard, T. (2011). Competencies and mathematical learning. In Ideas and inspiration for the development of mathematics teaching and learning in Denmark. IMFUFA, Roskilde University. http:// milne.ruc.dk/imfufatekster/pdf/485web_b.pdf

Niss, M., \& Højgaard, T. (2019). Mathematical competencies revisited. Educational Studies in Mathematics, 102(1), 9-28. https://doi.org/10.1007/s10649-019-09903-9

Niss, M., \& Jablonka, E. (2014). Mathematical literacy. In S. Lerman (Ed.), Encyclopedia of mathematics education (pp. 391-396). Springer. https://doi.org/10.1007/978-94-007-4978-8 100

OECD. (2019). Higher education in Mexico. In Labour market relevance and outcomes. OECD Publishing. https://doi.org/10.1787/9789264309432-en

Rothbauer, P. M. (2008). Triangulation. In L. M. Given (Ed.), The Sage encyclopedia of qualitative research methods (vol. 2, pp. 892-894). Sage.

Sharma, S. (2017). Definitions and models of statistical literacy: a literature review. Open Review of Educational Research, 4(1), 118-133. https://doi.org/10.1080/23265507.2017.1354313

Skovsmose, O. (1994). Towards a critical mathematics education. Educational Studies in Mathematics, 27(1), 35-57. https://doi.org/10.1007/BF01284527

Skovsmose, O. (1998). Linking mathematics education and democracy: Citizenship, mathematical archaeology, mathemacy and deliberative interaction. Zentralblatt für Didaktik der Mathematik, 30(6), 195-203. https:// doi.org/10.1007/s11858-998-0010-6

Watson, J. M., \& Callingham, R. (2003). Statistical literacy: A complex hierarchical construct. Statistics Education Research Journal, 2(2), 3-46.

Zeuner, C., Pabst, A., \& Benz-Gydat, M. (2020). Numeracy practices and vulnerability in old age: Interdependencies and reciprocal effects. ZDM-Mathematics Education, 52(3), 501-513. https://doi.org/ $10.1007 / \mathrm{s} 11858-019-01121-0$

Publisher's note Springer Nature remains neutral with regard to jurisdictional claims in published maps and institutional affiliations. 